\title{
The impact of salt, fat and sugar levels on toddler food intake
}

\author{
Sofia Bouhlal, Sylvie Issanchou and Sophie Nicklaus* \\ Centre des Sciences du Goût et de l'Alimentation, UMR6265 CNRS, UMR1324 INRA, Université de Bourgogne, Agrosup Dijon, \\ F-21000 Dijon, France
}

(Received 30 April 2010 - Revised 17 August 2010 - Accepted 25 August 2010 - First published online 7 December 2010)

\section{Abstract}

Understanding the early determinants of food intake, in particular the role of food sensory quality, is a necessary step to improve the prevention of unhealthy food habits. However, the extent to which food intake varies according to salt, fat and sugar content is imperfectly known. The present study aimed at evaluating whether toddler food intake varied during lunches or snacks in which salt, fat or sugar contents had been modified in common foods. Seventy-four children (30 (SE 0.5) months old) participated in the study in their usual day-care centres. Every other week, they were served lunches composed, among other items, of green beans and pasta with varying salt $(0,0.6$ and $1.2 \%$ added salt $)$ or fat $(0,2.5$ and $5 \%$ added butter) levels and afternoon snacks composed of fruit puree varying in sugar level (0, 5 and 10\% added sugar). During each meal, children could eat as much as they wanted from the target foods. Each food was weighed before and after the meal. Salt level had a positive impact on the intake of the target foods. On the contrary, no impact of added fat or added sugar levels was observed. This implies that fat and sugar addition could be avoided in foods for children without having an impact on palatability, allowing the energy density of children's diet to be limited. Salt addition should be limited, but its suppression in vegetables, whose intake is to be promoted, should be considered cautiously.

Key words: Children: Food intake: Salt: Fat: Sugar: BMI

Over the past few years, many countries have developed governmental policies aimed at decreasing the intake of salt-rich, fat-rich and sugar-rich foods ${ }^{(1)}$. In France in particular, the National Nutrition and Health Programme aims at limiting the quantity of salt, fat and sugar in foods $^{(2)}$. However, data measuring the impact of these reductions on food consumption, in particular in young children, are not available. Regarding the influence of sensory properties of foods on intake, especially in young children ${ }^{(3)}$, and the importance of early childhood in the development of long-standing food behaviour ${ }^{(4)}$, studying the impact of the recommendations on child food intake seems necessary. Few studies to date have evaluated the link between ingredient levels and intake especially among young children. In the present context of the universal prevalence of paediatric obesity and of the wide availability of palatable processed foods, it is essential to take into account the sensory drivers of eating.

In infants, previous studies using aqueous solutions showed that a preference for salty taste in a solution emerges at about the age of 4 months and persists till the age of 2 years ${ }^{(5-7)}$. Unlike what is observed for salty taste, humans exhibit an innate preference for sweet solutions, already observed a few hours after birth ${ }^{(8)}$, with newborn babies preferring highly sweet solutions ${ }^{(9)}$. Furthermore, during the first year of life, sweet and salty solutions are consumed on average more than water ${ }^{(7)}$. In children under the age of 2 years, sweet solutions generally elicit acceptance ${ }^{(10)}$, and the sweeter the solution the more they consume ${ }^{(11)}$. This preference may be linked to a high consumption of sweet foods: 4-year-old children who prefer the sweetest solution choose the sweetest apple juice at snack time ${ }^{(12)}$.

Beyond studies using solutions, research on foods showed that the preference for salt in foods, which appears at the age of 6 months, is reinforced by repeated exposure to salty foods, at least till 12 months of age ${ }^{(13)}$. Moreover, a context-specific preference for salt appears in early childhood. On the one hand, 2-year-old children tend to ingest more salty soup and carrots than the plain versions. On the other hand, children between 3 and 6 years old reject salty solutions but not salty soup ${ }^{(10,14)}$. This suggests the emergence of a preference for salty solutions between 3 and 6 months, followed by a preference for salty over non-salty versions of foods.

In other respects, fat-rich and sugar-rich foods, frequently associated with the high prevalence of overweight and obesity, are both highly palatable and appealing ${ }^{(15)}$, 
while providing dietary energy at low cost ${ }^{(16)}$. Sugar and fat are liked food features by children and the sweet and fat taste preference in childhood can be explained by the pleasure or by the energy they provide, considering the energy needs while growing ${ }^{(17)}$. Furthermore, an agerelated decline in sweet preference was documented: it is high in childhood ${ }^{(18)}$ and early adolescence and decreases in early adulthood ${ }^{(19)}$. As far as fat is concerned, it has positive post-ingestive consequences, since it conditions the preference for new flavours in preschool children ${ }^{(20,21)}$. However, the impact of fat level on child preference was not studied directly as was that of salt or sugar level. In a recent study, decreasing the fat content of a food (to decrease its energy density) was associated with a decrease in energy intake and also with a slight increase in weight intake in relation to energy compensation ${ }^{(22)}$. Moreover, child preference and consumption of fats appear to be linked to those of their parents and to their own BMI ${ }^{(23)}$.

The present study aims at evaluating the impact of salt, fat or sugar levels in common foods on children's intake, during a normal meal in a familiar environment. The general hypothesis is that salt, fat and sugar increase food palatability, which can potentially lead to an increase of food intake ${ }^{(24)}$. Three ingredient levels were studied: no addition, usual level used while preparing foods for children and twice the usual level. Our hypotheses were that children would (i) consume more of the saltier version and less of the salt-free one than of the usual one and (ii) consume more of the high-fat version and less of the fat-free one compared with the usual one considering that a positive effect of fat on palatability might be observed. Concerning added sugar variations, they were tested in a fruit purée. It could be supposed that children would (iii) consume more of the sweeter versions of this food than of the unsweetened version. Moreover, the existence of a food-specific effect of ingredient level on intake can be hypothesised, as for instance context-specific effects were shown for salt preference. In particular, the ingredient level effect may be different according to the hedonic value of the target food, since sensory variations in a liked food might affect the intake differently compared with in one that is rather disliked. Hence, variations of salt and fat were tested in two foods: one vegetable and one starchy food.

\section{Participants and methods}

\section{Participants}

All children attending one of three nurseries in Dijon (France) were proposed to take part in the present experiment. The children's body weight $(\mathrm{kg})$ and height $(\mathrm{m})$ were measured by the nursery doctor and $z$-scores for BMI were calculated using the French and International Obesity Task Force standards for child overweight and obesity $^{(25)}$. Their parents received an information sheet and signed a consent form. One of the children's parents did not allow their child participate due to food allergies. The study procedure was conducted according to the guidelines laid down in the Declaration of Helsinki, and approved by a local ethical committee (Comité de Protection des Personnes Est I Bourgogne).

A total of seventy-four children (forty-two girls and thirty-two boys) participated in the study. Their average age was 30 (se 4) months old (range 18-37 months), with average BMI of 15.9 (SE 0.1$) \mathrm{kg} / \mathrm{m}^{2}$ (range $13.5-$ $18.9 \mathrm{~kg} / \mathrm{m}^{2}$ ) and average BMI $z$-score -0.2 (SE 0.1 ) (range $-2 \cdot 3-2 \cdot 0$ ).

\section{General experimental design}

The present study aimed at evaluating toddler food intake according to variations of salt, fat and sugar levels in usual foods in a natural setting. It took place in the children's usual nursery in order to minimise the effects due to context changes. Before the beginning of the study, the experimenters visited the nurseries several times in order for the children and the nursery staff to become familiar to them. The nurses were asked to behave as normal (keep an eye on the children during the meal and help maintain calm conditions). Moreover, they were instructed neither to exhort children to eat nor to urge them to eat. Children were seated by groups of four to six around a table and one nurse was in charge of one table as usual. All the children were able to eat alone with a spoon or a fork, without any help. All the menu items were prepared in each nursery kitchen by the nursery cook and were pre-weighed by experimenters before lunch. The children could eat as much as they wanted from the target foods by asking for additional servings if they wanted to, which was a common practice in each nursery. All the servings were registered during the meal or snack for each child on a record sheet. Intake $(\mathrm{g})$ of each food item of the lunch or snack was measured by weighing each food before and after consumption to the nearest $1 \mathrm{~g}$ (Soehnle, Leifheit Group, Germany). The nurses were blind to the modifications brought to the target foods.

Added salt and fat level variations during lunches: procedure. For salt or fat level variations, the target foods were green beans and pasta served at lunch. The experimental fixed menu was served every other week at 11.00 hours. It was composed of vegetable salad (a unique serving of $50 \mathrm{~g}$ ), chicken (a unique serving of $50 \mathrm{~g}$ ), green beans (an initial serving of $50 \mathrm{~g}$ and up to a complement of $125 \mathrm{~g}$ on the basis of $25 \mathrm{~g}$ for each additional serving), pasta (an initial serving of $50 \mathrm{~g}$ and up to a complement of $125 \mathrm{~g}$ on the basis of $25 \mathrm{~g}$ for each additional serving), yogurt (a unique serving of $125 \mathrm{~g}$ ), bread (ad libitum) and water (ad libitum). Portion sizes were adapted from the French guidelines for school canteen usage ${ }^{(26)}$. Vegetable salad and chicken were prepared as usual. Frozen green beans and pasta (small macaroni) were boiled with tap 
water (11 and $8 \mathrm{~min}$, respectively) without adding salt, oil or any flavouring. The experimenters further added salt or butter according to the experimental design and stirred the foods homogeneously.

Added salt level variations were studied in a first series of five observations and added fat level variations were studied in a second series of five observations. According to the nursery cooks, the average levels used for preparing foods for children were $0.6 \mathrm{~g}$ of salt/100 $\mathrm{g}$ of food and $2.5 \mathrm{~g}$ of butter/ $100 \mathrm{~g}$ of food. These usual levels were then chosen to be the 'control' values $(0.6 \%$ salt and $2.5 \%$ butter). We varied these levels by adding no salt or no fat $(0 \%)$ or by doubling them $(1.2 \%$ salt and $5 \%$ butter). Thus, three levels were tested for each target food and each ingredient. For both the series, the first observation was a control for salt and fat. Then the order of the four other observations was different across the nurseries (Table 1). For each observation, salt or fat level varied only in green beans or in pasta. For instance, if salt level varied in green beans, their fat content was the control level and pasta was served with control levels of salt and of fat.

After the serving of the fixed amount of vegetable salad, children were served chicken and green beans; afterwards, they were served pasta and then the yogurt. This order of presentation was chosen in order to allow the children to eat the vegetable first, which was generally less consumed by children compared with pasta ${ }^{(27)}$ - this also being the usual practice in the nurseries.

Added sugar level variation during snack time: procedure. For sugar level variations, the target food was a fruit purée served during the afternoon snack every other week at 15.30 hours. In order to evaluate the children's intake depending on added sugar level, an unsweetened apple-peach purée (Hero, 26400 ALLEX, France) was chosen and three levels of added sugar were tested. One level corresponded to the plain fruit purée (unsweetened; variant named $0 \%$ ); for the second one, $5 \mathrm{~g}$ of sugar was added to $100 \mathrm{~g}$ of purée (variant named $5 \%$ ); and for the third one, $10 \mathrm{~g}$ of sugar was added to $100 \mathrm{~g}$ of purée (variant named $10 \%$ ). The order of presentation for the three variants was different across the nurseries. A first portion of $100 \mathrm{~g}$ was served and additional servings of $50 \mathrm{~g}$ were available, up to a complement of $200 \mathrm{~g}$. Afterwards, the children were served a maximum of $20 \mathrm{~g}$ of biscuits then ad libitum milk and/or water.

\section{Sensory description of food variants}

A sensory description of the food variants was performed with an adult panel. In fact, regarding the young age of the children participating in the main study, sensory description was not possible ${ }^{(28,29)}$. A trained sensory panel of twelve adults (six women and six men), aged between 27 and 66 years, evaluated all variants of the three target foods. The panel members were screened for their olfactory abilities, their abilities to perceive and identify the basic tastes and for their capability to use a linear scale to score intensities. The intensity scales from the Spectrum $^{\mathrm{TM}}$ method for descriptive analysis were used to describe sweet, salty, sour and bitter tastes ${ }^{(30)}$. A Spectrum $^{\mathrm{TM}}$-like scale was developed for fattiness perception. After eleven training sessions on the way to use the scale for each taste or perception, the panellists were asked to score the perceived intensities of each variant of each target food presented monadically, from 'not perceived' (0) to 'very intense' (10). Two replications were performed.

\section{Statistical analyses}

Statistical analyses were carried out using SAS System for Windows version 9.1 (SAS Institute, Inc., Cary, NC, USA). Significance was set at $P<0.05$. For sensory description, an ANOVA was performed using a linear model (SAS GLM

Table 1. Experimental design for varying added $(\mathrm{g} / 100 \mathrm{~g})$ salt and fat (butter) in green beans and pasta for each nursery

\begin{tabular}{|c|c|c|c|c|c|c|c|c|c|c|c|c|}
\hline \multirow[b]{3}{*}{ Nursery } & \multirow[b]{3}{*}{ Food } & \multirow[b]{3}{*}{ Ingredient } & \multicolumn{5}{|c|}{ Salt level variations } & \multicolumn{5}{|c|}{ Fat level variations } \\
\hline & & & \multicolumn{10}{|c|}{ Observation number } \\
\hline & & & $1^{*}$ & 2 & 3 & 4 & 5 & $6^{*}$ & 7 & 8 & 9 & 10 \\
\hline \multirow[t]{4}{*}{ A } & Green beans & Salt & 0.6 & 0.6 & 0 & 0.6 & $1 \cdot 2$ & 0.6 & 0.6 & 0.6 & 0.6 & 0.6 \\
\hline & & Butter & $2 \cdot 5$ & 2.5 & 2.5 & 2.5 & $2 \cdot 5$ & 2.5 & 5 & 2.5 & 0 & 2.5 \\
\hline & Pasta & Salt & 0.6 & $1 \cdot 2$ & 0.6 & 0 & 0.6 & 0.6 & 0.6 & 0.6 & 0.6 & 0.6 \\
\hline & & Butter & 2.5 & $2 \cdot 5$ & 2.5 & 2.5 & $2 \cdot 5$ & 2.5 & 2.5 & 0 & 2.5 & 5 \\
\hline \multirow[t]{4}{*}{ B } & Green beans & Salt & 0.6 & 0 & 0.6 & 1.2 & 0.6 & 0.6 & 0.6 & 0.6 & 0.6 & 0.6 \\
\hline & & Butter & $2 \cdot 5$ & 2.5 & 2.5 & $2 \cdot 5$ & $2 \cdot 5$ & 2.5 & 2.5 & 5 & $2 \cdot 5$ & 0 \\
\hline & Pasta & Salt & 0.6 & 0.6 & 1.2 & 0.6 & 0 & 0.6 & 0.6 & 0.6 & 0.6 & 0.6 \\
\hline & & Butter & $2 \cdot 5$ & 2.5 & 2.5 & 2.5 & $2 \cdot 5$ & 2.5 & 0 & 2.5 & 5 & $2 \cdot 5$ \\
\hline \multirow[t]{4}{*}{ C } & Green beans & Salt & 0.6 & 0.6 & 1.2 & 0.6 & 0 & 0.6 & 0.6 & 0.6 & 0.6 & 0.6 \\
\hline & & Butter & $2 \cdot 5$ & 2.5 & 2.5 & 2.5 & $2 \cdot 5$ & 2.5 & 0 & 2.5 & 5 & $2 \cdot 5$ \\
\hline & Pasta & Salt & 0.6 & 0 & 0.6 & 1.2 & 0.6 & 0.6 & 0.6 & 0.6 & 0.6 & 0.6 \\
\hline & & Butter & $2 \cdot 5$ & 2.5 & 2.5 & 2.5 & $2 \cdot 5$ & 2.5 & $2 \cdot 5$ & 5 & 2.5 & 0 \\
\hline
\end{tabular}

${ }^{*}$ Control observations. 
procedure) for each taste quality and for the three variants of each target food. The model was:

Taste quality $=$ panellist + ingredient level + panellist

$$
\times \text { ingredient level }+ \text { error, }
$$

where 'panellist' was considered as a random effect. Means for the three variants were compared with one another using $t$ tests.

To analyse the children's consumption, the outcome was intake $(\mathrm{g})$ of green beans, pasta or fruit purée. For each series, paired $t$ tests $\left(t_{\mathrm{df}}\right)$ were used to determine, over the five lunches, whether the average intake of green beans was different from the average intake of pasta. For each ingredient (fat, salt or sugar) and each target food intake (green beans, pasta or fruit purée), data were analysed using a mixed linear model (SAS Mixed procedure), with 'child effect' considered as random. The primary factor tested in the model was ingredient level. The children's BMI $z$-score was introduced as a covariate to evaluate to what extent it might affect the target food intake. Interactions between ingredient level and BMI $z$-score were investigated: if no significant effect was found, the interaction was removed from the model. The 'Empirical' option was specified so as to use a sandwich estimator for the variance-covariance matrix of the fixed-effect parameters. For the comparison of means, the Dunnett test was applied: the control variant $(0.6 \%$ added salt, $2.5 \%$ added butter or $5 \%$ added sugar) was compared with the other variants. Data are reported as mean values with their standard errors.

\section{Results}

\section{Sensory description of food variants}

Salt level variations in green beans and pasta. Saltiness intensity differed according to added salt levels in green beans and in pasta $(F(2,36)=71.47 ; \quad P<0.0001$ and $F(2,36)=95.52 ; P<0.0001$, respectively $)$ the three variants of each food were significantly different (Table 2). Moreover, the $0 \%$ added salt green beans were perceived as more sour $(F(2,36)=4.35 ; \quad P=0.02)$ and less fatty $(F(2,36)=17 \cdot 89 ; P<0 \cdot 0001)$ than the two other variants.

Fat level variations in green beans and pasta. Fattiness perception differed according to added fat levels in green beans and in pasta $(F(2,36)=4.10 ; \quad P=0.025$ and $F(2,36)=24 \cdot 30 ; \quad P<0 \cdot 0001$, respectively), as shown in Table 2. However, panellists were not able to distinguish the $2.5 \%$ and the $5 \%$ added fat green beans, whereas the three variants of pasta were distinguished from each other.

Sugar level variations in fruit purée. Sweetness intensity differed according to added sugar level in fruit purée $(F(2,36)=74.89 ; P<0.0001)$ as reported in Table 2: the three variants were significantly different, as the more the added sugar the higher the perceived sweetness. They also differed with regard to sourness and bitterness intensities, $\quad(F(2,36)=8.34 ; \quad P=0.0011$ and $F(2,36)=9 \cdot 57$; $P=0.0005$, respectively): the $0 \%$ added sugar variant was perceived more sour and more bitter than the two other variants.

\section{Children's intake during experimental lunches}

Intake when added salt level varied. From the initial sample of seventy-four children, only those who were present for at least two meals out of five were considered for the present analyses, resulting in a final group of sixty-six children. No child reached the maximum serving of $175 \mathrm{~g}$ for green beans and only $7 \%$ reached this maximum for pasta. A paired $t$ test comparing the average intake of green beans and pasta over the five lunches showed, as expected, that pasta intake, 87 (SE 4) g, was greater than that of green beans, $32(\mathrm{SE} 3) \mathrm{g}$, where $t_{65}=12.5$ $(P<0 \cdot 0001)$.

Table 2. Sensory description of food variants

\begin{tabular}{|c|c|c|c|c|c|c|c|}
\hline Food & Ingredient & Level (\%) & Salty* & Sweet & Sour & Bitter & Fatty \\
\hline \multirow[t]{6}{*}{ Green beans } & Salt & 0 & $0.25^{\mathrm{a}}$ & $0.38^{a}$ & $0.62^{b}$ & $0.21^{a}$ & $0.50^{a}$ \\
\hline & & 0.6 & $2 \cdot 10^{\mathrm{b}}$ & $0.59^{a}$ & $0.40^{a}$ & $0.15^{\mathrm{a}}$ & $1.15^{b}$ \\
\hline & & 1.2 & $3 \cdot 81^{c}$ & $0.55^{\mathrm{a}}$ & $0.49^{\mathrm{a}}$ & $0.17^{\mathrm{a}}$ & $1 \cdot 11^{b}$ \\
\hline & Butter & 0 & $2 \cdot 22^{a}$ & $0.76^{a}$ & $0.63^{a}$ & $0.18^{\mathrm{a}}$ & $0.77^{\mathrm{a}}$ \\
\hline & & 2.5 & $2 \cdot 24^{\mathrm{a}}$ & $0.73^{\mathrm{a}}$ & $0.44^{\mathrm{a}}$ & $0.17^{\mathrm{a}}$ & $1.08^{b}$ \\
\hline & & 5 & $2 \cdot 20^{\mathrm{a}}$ & $0.79^{\mathrm{a}}$ & $0.53^{\mathrm{a}}$ & $0.18^{\mathrm{a}}$ & $1 \cdot 16^{b}$ \\
\hline \multirow[t]{6}{*}{ Pasta } & Salt & 0 & $0.26^{a}$ & $0.69^{a}$ & $0.38^{a}$ & $0.21^{a}$ & $1.58^{\mathrm{a}}$ \\
\hline & & 0.6 & $2 \cdot 54^{\mathrm{b}}$ & $0.79^{\mathrm{a}}$ & $0.26^{a}$ & $0.14^{\mathrm{a}}$ & $1.90^{\mathrm{a}}$ \\
\hline & & 1.2 & $3.94^{c}$ & $0.86^{a}$ & $0.31^{a}$ & $0.44^{\mathrm{a}}$ & $2.29^{\mathrm{a}}$ \\
\hline & Butter & 0 & $2 \cdot 14^{a}$ & $0.54^{a}$ & $0.24^{a}$ & $0.07^{a}$ & $0.82^{\mathrm{a}}$ \\
\hline & & 2.5 & $2 \cdot 45^{\mathrm{a}}$ & $0.65^{\mathrm{a}}$ & $0.25^{a}$ & $0.05^{\mathrm{a}}$ & $1 \cdot 28^{b}$ \\
\hline & & 5 & $2 \cdot 47^{a}$ & $0.59^{a}$ & $0.32^{a}$ & $0.08^{a}$ & $1.99^{\mathrm{C}}$ \\
\hline \multirow[t]{3}{*}{ Fruit purée } & Sugar & 0 & $0 \cdot 19^{a}$ & $1.45^{\mathrm{a}}$ & $3.96^{\mathrm{b}}$ & $0.65^{\mathrm{b}}$ & $0.21^{a}$ \\
\hline & & 5 & $0.14^{\mathrm{a}}$ & $3 \cdot 10^{b}$ & $2 \cdot 84^{a}$ & $0.37^{\mathrm{a}}$ & $0.27^{\mathrm{a}}$ \\
\hline & & 10 & $0.12^{\mathrm{a}}$ & $4.64^{\mathrm{C}}$ & $2 \cdot 33^{\mathrm{a}}$ & $0.25^{a}$ & $0.34^{\mathrm{a}}$ \\
\hline
\end{tabular}


The impact of salt level variations on intake was evaluated separately for each target food. The results are shown in Fig. 1(a). Concerning green beans, the salt level had an impact on the intake $(F(2,106)=10 \cdot 89 ; P<0.0001 ; n$ 63): $0 \%$ salt green beans were less consumed than $0.6 \%$ salt green beans. Concerning pasta, the salt level also had an impact on the intake $(F(2,92)=3 \cdot 19 ; P=0 \cdot 045 ; n 60): 1 \cdot 2 \%$ salt pasta was more consumed than $0.6 \%$ salt pasta. Hence, the suppression of salt decreased green bean intake and the addition of salt increased pasta intake, compared with the usual salt level. Despite this difference in salt level effect observed through the analyses conducted separately for each target food, a global analysis performed on data of both target foods did not reveal a significant food $\times$ salt level interaction.

Intake when added fat level varied. From the initial sample of seventy-four children, only those who attended at least two meals out of five were considered for the present analyses, resulting in a final group of sixty-nine children. No child reached the maximum serving of $175 \mathrm{~g}$

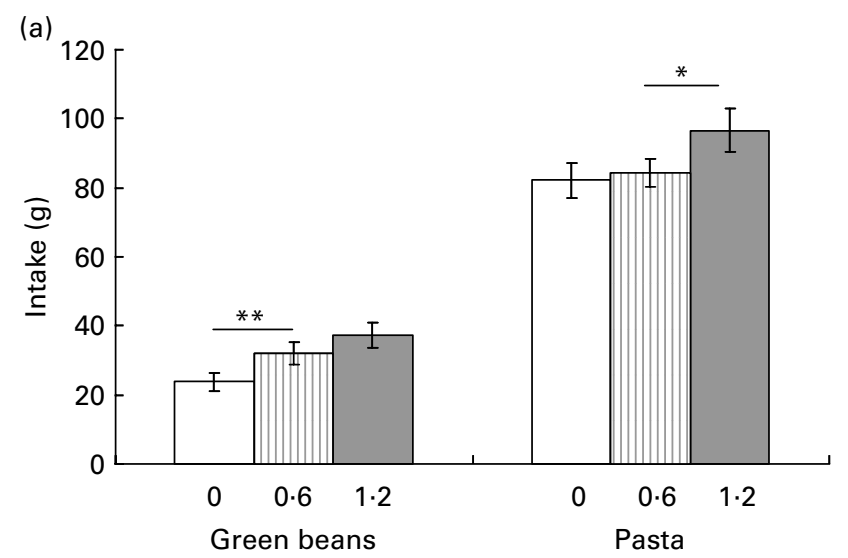

Added salt level (\%)

(b)

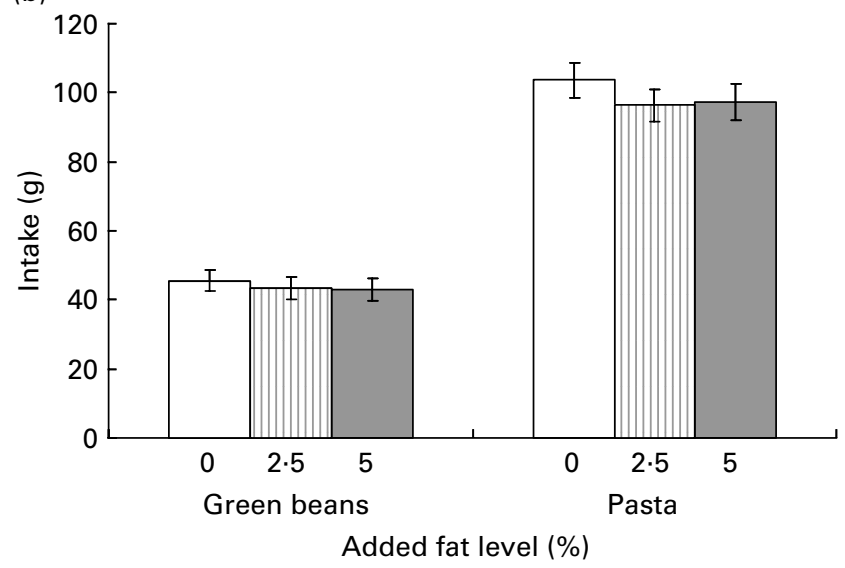

Fig. 1. Impact of added salt ((a) $0,0.6$ and $1.2 \%$ added salt) and added fat ((b) $0,2.5$ and $5 \%$ added butter) level on green bean and pasta intake in 2-3-year-old children (least squares mean values with their standard errors). For mean comparison, a Dunnett test was applied: the $0.6 \%$ added salt or the $2.5 \%$ added butter sample was compared with the other samples respectively for added salt and added fat level analysis. Mean values were significantly different: ${ }^{*} P<0.05 ;{ }^{* *} P<0.01$. for green beans and only $11 \%$ reached this maximum for pasta. A paired $t$ test comparing the average intake of green beans and pasta over the five lunches showed, as expected, that pasta intake, 99 ( $\mathrm{SE} 4$ ) g was greater than green bean intake, 43 ( $\mathrm{SE} 3) \mathrm{g}$, where $t_{68}=12.23(P<0.0001)$.

The impact of fat level variations on intake was evaluated separately for each target food. Fat level had an impact on neither the intake of green beans $(F(2,103)=0.45 ; \quad P=0.63 ; n$ 62) nor on that of pasta $(F(2,99)=0.48 ; P=0.62 ; n 60)$. The results are shown in Fig. 1(b).

\section{Children's intake during experimental snacks when added sugar level varied}

From the initial sample of seventy-four children, only those who attended the three snack sessions in which sugar level varied in fruit purée were considered for the present analysis ( $n$ 61). Only $4 \%$ of children reached the maximum serving of $300 \mathrm{~g}$ of fruit purée.

Sugar level variations did not have an impact on fruit purée intake $(F(2,120)=1 \cdot 43 ; P=0 \cdot 24)$, as shown in Fig. 2 .

\section{Effect of BMI z-score on intake}

The children's BMI $z$-score was not related to intake when added salt level varied, neither in green beans $(F(1,106)=0.78 ; P=0.38)$ nor in pasta $(F(1,92)=0.61$; $P=0 \cdot 44)$. When added fat level varied, BMI $z$-score did not affect the green bean intake $(F(1,103)=1 \cdot 77$; $P=0 \cdot 18)$, but it had an impact on pasta intake $(F(1,99)=6 \cdot 01 ; P=0 \cdot 01)$ : the higher the BMI $z$-score the higher the pasta intake. Further examination of data revealed that BMI $z$-score was especially related to intake of the 5\% added butter pasta. When added sugar level varied in fruit purée, no impact of BMI $z$-score on intake was observed $(F(1,120)=0 \cdot 32 ; P=0 \cdot 57)$.

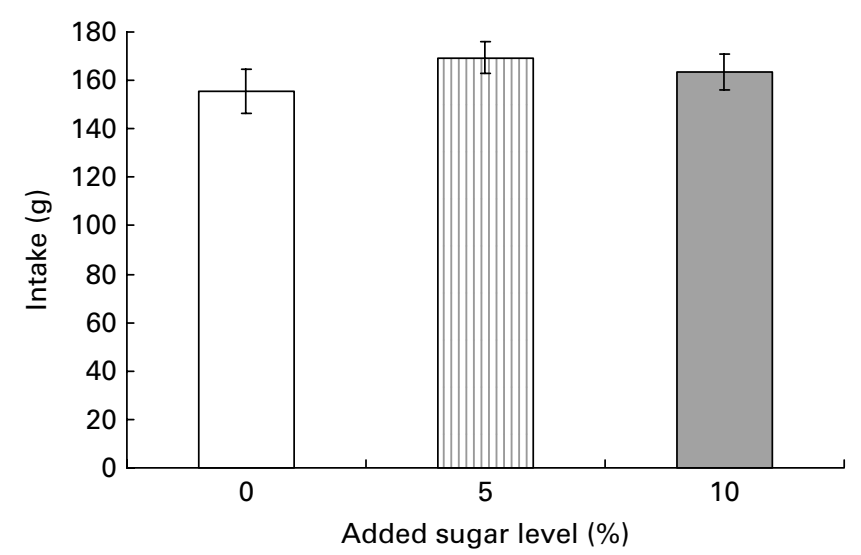

Fig. 2. Impact of added sugar level (0,5 and 10\%) on fruit purée intake in 2-3-year-old children (least squares mean values with their standard errors). For mean comparison, a Dunnett test was applied: the $5 \%$ added sugar sample was compared with the other samples. Mean values were not significantly different. 


\section{Discussion}

\section{Added salt and fat level variations}

The present study aimed at evaluating the impact of salt and fat variations on the intake of two different foods by 2- to 3-year-old children. Two main findings can be highlighted: first, salt had an impact on intake but fat did not; secondly, intake increased with salt level (compared with the usual salt level, a suppression of salt induced a $25 \%$ decrease in green bean intake, whereas an addition of salt induced a $15 \%$ increase in pasta intake). Moreover, pasta was more consumed than green beans.

Salt $(\mathrm{NaCl})$ is known as an appetite stimulator, a taste modulator and a flavour enhancer ${ }^{(31)}$. An increased preference for salty over non-salty foods appears at 2-3 years of age ${ }^{(5)}$, leading to a preference for saltier foods in children than in adults, whether in a liquid ${ }^{(32)}$ or in a solid medium $^{(33)}$. In addition to the fact that salt preference is context specific in infants and children ${ }^{(10)}$, it may also be food specific. In fact, other researchers showed that the perception and acceptability of saltiness are product specific $^{(34)}$. In the present experiment, the hypothesis of a food-specific effect of salt is not confirmed (no significant food $\times$ salt level interaction). However, when salt was suppressed in green beans, intake was reduced by $25 \%$ and was very low $(24 \mathrm{~g})$, whereas intake was still high in pasta (82 g). Here, suppression of salt appeared critical in a not well-liked food, whereas it was not the case in a liked food. Salt is also known to be a taste modulator, as perceived bitterness can be suppressed by salt addition ${ }^{(35)}$. Here, variations in bitterness could have explained the decreasing intake of green beans when no salt was added, but the trained panel scored bitterness in green beans as very low (mean bitterness intensity over the three variants of $0 \cdot 18$ on a scale from 0 to 10) and failed to find any difference in bitterness between green bean samples. However, the unsalted green beans were scored sourer and less fatty. We hence cannot exclude that variations in tastes, other than salty taste, have an impact on children, which accounts for the decreased intake of the unsalted version, whereas pasta samples differed clearly only in salty taste.

In other respects, it seems that human avidity for salty taste is not due to a 'sodium appetite' (a desire for sodium) as is the case for animals, but is most probably related to a 'salt appetite' (seeking the taste of $\mathrm{NaCl}$ ), an attraction to the taste of salt independently from the subject's Na status (for a review, see Leshem ${ }^{(31)}$ ). Nevertheless, due to its potential long-term detrimental effect on health $^{(36)}$, strategies to reduce $\mathrm{Na}$ intake have been developed $^{(37)}$. One of them is related to the flavour-enhancing properties of salt: adding an odorant associated with saltiness through previous experience (i.e. bacon flavour) to a slightly salted solution enhanced its perceived saltiness ${ }^{(38)}$. This strategy would be interesting to promote vegetable intake in children by maintaining a salty perception without adding large amounts of salt.

Concerning the absence of fat impact on intake, two hypotheses can be formulated: either the changes of fat content over different meals were not perceived by children or fat is not an immediate hedonic determinant of food intake in children. Here, the trained panel could differentiate the 'fattiness perception' in the three samples of pasta varying in fat content, and concerning green beans, the panel could only differentiate the $0 \%$ added butter green beans from the other two samples. Despite these sensory differences, children's intake was not affected by fat content. Hence, fat sensory properties may not be well detected by human subjects ${ }^{(3,39)}$. In fact, studies in adults using dairy products showed that participants could not distinguish between the samples according to their fat content, but liked the fattiest samples ${ }^{(39,40)}$. Yet, it is admitted that the preference for high-fat foods is not based on a 'conscious' perception of fat content ${ }^{(41)}$. However, as for salt, fat in foods is also known to enhance their flavour and their acceptability and may lead to an increased preference, and by extension, to an increased intake ${ }^{(15,20,21)}$. However, we did not observe such an effect. That the fat level in food is poorly perceived is also revealed in a study examining the link between energy density associated with varying fat content and intake of macaroni and cheese in 2- to 5-year-old children $^{(22)}$. Intake for two fat levels $(39 \cdot 8$ and $19 \cdot 7 \%$ total fat) was measured in separate meals: when the fat level decreased, a small but significant increase in intake was observed $(+7 \%)$. In the present study, the addition of $5 \%$ butter corresponded to $4.1 \%$ fat: thus when total fat varied from 4.1 to $0 \%$, a $6.5 \%$ increase in intake was noticed, which did not reach significance $(P=0 \cdot 27)$. Nevertheless, these fat levels correspond to those generally used in nursery canteens for preparing food for children. With such a range of fat content, the presentation of an ad libitum meal was not associated with children's adjustment for varying palatability and/or energy density in the short term. Similarly, concerning the green beans, the decrease in fat content in green beans (from $4 \cdot 1$ to $0 \%$ total fat) resulted in a $4.5 \%$ increase in intake, which again was NS. Hence, contrarily to our initial hypothesis, no direct effect of fat on intake was observed.

The present data also showed that preschool children with a higher BMI $z$-score consumed more pasta when fat level was higher, thus confirming the previous result highlighting that fatter children prefer high-fat foods ${ }^{(23)}$. Moreover, child 'fat appetite' was previously linked to their parents' body mass, and a link between child preference for high-fat snack foods and their consumption of a high percentage of total energy from fat was also shown ${ }^{(23)}$. A similar link between the preference for high-fat foods and BMI was described in 9- to 12-yearold children ${ }^{(42)}$. Longitudinal approaches would help us to understand the contribution of fatty food intake in 
the development of obesity. Alternatively, this effect could be related to sensitivity to fatty acids which is lower in heavier adult subjects, as reported recently ${ }^{(43)}$. To date, such an effect has not been studied in children.

In other respects, two main reasons are generally put forward to explain the low intake of vegetables among young children: the first one is the absence of reinforcement resulting from their low energy density ${ }^{(44,45)}$ and the second one is their disliked taste that might be due to their bitterness ${ }^{(46)}$ (as was discussed earlier). The lower intake of green beans compared with that of pasta confirms the previous data showing that, in a free choice situation, vegetables are among the least selected foods by young children compared with starchy foods and animal products ${ }^{(27)}$, despite their recognised beneficial effects on health ${ }^{(47)}$. Moreover, the low variety of consumed vegetables observed in early childhood persists through to adulthood ${ }^{(4,45)}$. Hence, increasing vegetable intake by children is a major issue and more knowledge is needed about factors influencing their acceptance. Several studies have investigated the methods for improving preschool children's vegetable consumption by evaluating the effect of learning practices (for a review, see Havermans ${ }^{(48)}$ ) as well as the effect of varying ways of preparation ${ }^{(49)}$. The last study showed that children prefer boiled vegetables, which was the preparation method chosen for the present study. Clearly, sensory properties of vegetables are largely modified by preparation and much is to be learned to fully understand their impact on vegetable intake by children.

\section{Added sugar level variations}

The present findings indicate that 2- to 3-year-old children's intake of a fruit purée was not affected by its added sugar content. Contrarily to our initial hypothesis, no increase in intake with increasing added sugar level was observed. With regard to the recognised effect of sweetening on enhancing the palatability of foods, three hypotheses may explain this result. First, when tasting the fruit purée, children may not have perceived the difference in sweetness intensity between the variants over separate snack days. However, the results obtained by the trained panel showed a clear distinction between the samples in terms of sweetness and to a lesser extent of sourness and bitterness. Secondly, the unsweetened variant may have been sweet enough for children to like and consume it, due to the natural sweet taste of the fruits. Thirdly, the intake of all versions of the fruit purée, $163 \mathrm{~g}$ on an average, was far above the median portion of commercialised products $(100 \mathrm{~g})$, therefore suggesting a ceiling effect.

Individual differences in liking for sweet taste were previously reported ${ }^{(24,50)}$. In a study comparing children's and adults' liking related to sugar concentration, responses fitted an inverted U-shape for preference with a maximum hedonic response for both groups, but preferred concentrations were higher for children than for adults ${ }^{(17)}$. In the present study, taken as a group, the intake by children levelled up with increasing added sugar level, with neither increase nor decrease depending on the sugar level, suggesting an indifference to sugar level. Hence, the hypothesis of a tolerance zone to sweet taste, in fact a 'large tolerance plateau', could be considered.

The high consumption of fruit puree is consistent with the fact that liking sweet-tasting foods is strongly linked to the child's basic biology (for a review, see Pepino \& Mennella ${ }^{(51)}$, and the absence of sugar level effect on intake is in line with the observation that most studies in adults failed to find an effect of sugar level on food intake $^{(24)}$. That is to say, one may not need to add sugar to fruit purée to enhance its intake. Furthermore, an interventional study in children aged 7-11 years showed that the more children consume sweetened drinks, the higher their risk of being overweight or obese ${ }^{(52)}$. Altogether, these findings suggest that in order to promote a healthy energy balance in children and to favour the consumption of healthy foods such as fruits, limiting or suppressing added sugar may help to prevent excess energy input without altering their intake. Similar data concerning different foods with different textures and different levels of sugar, such as drinks, cakes or dairy products would also be useful and should be investigated.

\section{Methodological considerations}

Here, an initial portion of $50 \mathrm{~g}$ was served of green beans and pasta and of $100 \mathrm{~g}$ of fruit purée. This did not lead to a systematic consumption of this portion: at the group level, green bean intake was always below the served portion, revealing that children did not clean up their plates but pasta and fruit purée intake was always above the served portions; so, children did not hesitate to ask for additional servings. The fact that 'additional serving' was a usual practice in nurseries could account for this observation, which is consistent with the results showing that children below 3 years old are not systematically influenced by portion size ${ }^{(53)}$. Thus, this procedure seems appropriate to observe the effects of subtle sensory manipulations.

Conducting such a study where children did not have the opportunity to compare variants directly, no difference in intake was observed when fat and sugar level varied. Another protocol using a paired preference test might have yielded different results. However, studying intake appears more relevant in order to understand the actual children's behaviour in response to a given level of ingredient, because it is closer to everyday eating experiences where children are not able to compare the products. 


\section{General conclusion}

Salt level had a positive impact on the intake of target foods, whereas fat (butter) content did not, either for green beans or for pasta. Besides, sugar level did not elicit any difference in the intake of fruit purée. That is to say, lowering the addition of fat or sugar while preparing children's foods, especially when the food is liked without any extra ingredients being added (such as starchy foods or fruit purée), may appear to be a useful way to reduce energy intake and to avoid the development of a habit of consuming foods rich in fat and sugar. Furthermore, these findings suggest that there is no need to add salt to pasta which is consumed anyway. On the contrary, salt suppression in vegetables, whose intake is to be promoted, should be considered cautiously. Alternatively, seasoning vegetables using salt-associated spices may be an efficient and necessary strategy to promote their consumption in children. Hence, nutritional policies regarding the use of salt, fat and sugar aimed at children could take these results into account and could emphasise that salt addition should be limited and that fat and sugar addition can be avoided, helping to prevent obesity from an early age on and to establish healthier food habits.

\section{Acknowledgements}

The present work was funded by the Nutrition, Chemical Food Safety and Consumer Behaviour Division of INRA (French National Institute for Agronomical Research) and the Regional Council of Burgundy. The authors thank the Early Childhood Department of the city of Dijon as well as the nursery directors and caregivers. Cooks from the nurseries and from the Dijon University Hospital central kitchen are especially thanked for their support. S. B. thanks the children and their parents who took part in the present study; Dr Vincent Boggio for his general support and his advice; Claire Chabanet for her assistance on conducting statistical analyses; Christophe Martin for conducting sensory profiling; Valérie Feyen, Emilie Szleper, Céline Magnan, Camille Schwartz, Audrey Perot and Françoise Durey are thanked for their assistance with food preparation and data collection. S. B. and S. N. designed the study with the help of S. I. The collection of data, the data analysis and the writing of the paper were performed by S. B. and S. N. with the help of S. I. The authors have no conflict of interest to disclose.

\section{References}

1. World Health Organization (2003) Diet, Nutrition and the Prevention of Chronic Diseases. WHO Technical Report Series. Geneva: WHO.

2. French Ministry of Health (2006) Second National Nutrition and Health Programme (2006-2010). Paris: French Ministry of Health.
3. Drewnowski A (1997) Taste preference and food intake. Annu Rev Nutr 17, 237-253.

4. Nicklaus S, Boggio V, Chabanet C, et al. (2005) A prospective study of food variety seeking in childhood, adolescence and early adult life. Appetite 44, 289-297.

5. Beauchamp GK, Cowart BJ \& Moran M (1986) Developmental changes in salt acceptability in human infants. Dev Psychobiol 19, 17-25.

6. Beauchamp GK, Cowart BJ, Mennella JA, et al. (1994) Infant salt taste: developmental, methodogical, and contextual factors. Dev Psychobiol 27, 353-365.

7. Schwartz C, Issanchou S \& Nicklaus S (2009) Developmental changes in the acceptance of the five basic tastes in the first year of life. Br J Nutr 102, 1375-1385.

8. Steiner JE (1979) Human facial expressions in response to taste and smell stimulation. Adv Child Dev Behav 13, $257-295$.

9. Ganchrow JR, Steiner JE \& Daher M (1983) Neonatal facial expressions in response to different qualities and intensities of gustatory stimuli. Infant Behav Dev 6, 473-484.

10. Beauchamp GK \& Moran M (1984) Acceptance of sweet and salty tastes in 2-year-old children. Appetite 5, 291-305.

11. Vasquez M, Pearson PB \& Beauchamp GK (1982) Flavor preferences in malnourished Mexican infants. Physiol Behav 28, 513-519.

12. Olson CM \& Gemmill KP (1981) Association of sweet preference and food selection among four to five year old children. Ecol Food Nutr 11, 145-150.

13. Harris G \& Booth DA (1987) Infants' preference for salt in food: its dependence upon recent dietary experience. J Reprod Infant Psychol 5, 97-104.

14. Cowart BJ \& Beauchamp GK (1986) The importance of sensory context in young children's acceptance of salty tastes. Child Dev 57, 1034-1039.

15. Mela DJ (1990) Sensory preferences for fats: what, who, why? Food Qual Pref 2, 95-101.

16. Drewnowski A (2003) Fat and sugar: an economic analysis. J Nutr 133, 838S-840S.

17. de Graaf C \& Zandstra EH (1999) Sweetness intensity and pleasantness in children, adolescents, and adults. Physiol Behav 67, 513-520.

18. Pepino MY \& Mennella JA (2005) Factors contributing to individual differences in sucrose preference. Chem Senses 30, I319-I320.

19. Desor JA \& Beauchamp GK (1987) Longitudinal changes in sweet preferences in humans. Physiol Behav 39, 639-641.

20. Johnson SL, McPhee L \& Birch LL (1991) Conditioned preferences: young children prefer flavors associated with high dietary fat. Physiol Behav 50, 1245-1251.

21. Kern DL, McPhee L, Fisher J, et al. (1993) The postingestive consequences of fat condition preferences for flavors associated with high dietary fat. Physiol Behav 54, $71-76$.

22. Leahy KE, Birch LL \& Rolls BJ (2008) Reducing the energy density of an entrée decreases children's energy intake at lunch. J Am Diet Assoc 108, 41-48.

23. Fisher JO \& Birch JL (1995) Fat preferences and fat consumption of 3 to 5 year old children are related to parent adiposity. J Am Diet Assoc 95, 759-764.

24. Sørensen LB, Møller P, Flint A, et al. (2003) Effect of sensory perception of foods on appetite and food intake: a review of studies on humans. Int J Obes 27, 1152-1166.

25. Thibault H, Rolland-Cachera MF, Castetbon K, et al. (2004) CalIMCo2: Logiciel d'évaluation et de suivi de la corpulence des enfants (CALIMCO: Software for Evaluation and Monitoring of Children's Corpulence). PNNS 2004. Paris. Ministère de la Santé. 
26. Groupe d'Etude des Marchés de Restauration Collective et de Nutrition (2007) Recommandations relatives à la nutrition (Recommendations in Terms of Nutrition). Observatoire Economique de l'Achat Public. Paris: Ministère de l'Economie des Finances et de l'Industrie.

27. Nicklaus S, Boggio V \& Issanchou S (2005) Food choices at lunch during the third year of life: high selection of animal and starchy foods but avoidance of vegetables. Acta Pcediatr 94, 943-951.

28. ASTM (2003) Standard Guide for Sensory Evaluation of Products by Children. West Conshohocken, PA: ASTM.

29. Guinard J-X (2001) Sensory and consumer testing with children. Trends Food Sci Technol 11, 273-283.

30. Meilgaard M, Civille GV \& Carr BT (1991) Sensory Evaluation Techniques. Boca Raton, FL: CRC Press.

31. Leshem M (2009) Biobehavior of the human love of salt. Neurosci Biobehav Rev 33, 1-17.

32. Beauchamp GK \& Cowart BJ (1990) Preference for high salt concentrations among children. Dev Psychol 26, 539-545.

33. Verma P, Mittal S, Ghildiyal A, et al. (2007) Salt preference: age and sex related variability. Indian J Physiol Pharmacol 51, $91-95$.

34. Adams SO, Maller O \& Cardello AV (1995) Consumer acceptance of foods lower in sodium. J Am Diet Assoc 95 , 447-453.

35. Breslin PAS \& Beauchamp GK (1995) Suppression of bitterness by sodium: variation among bitter taste stimuli. Chem Senses 20, 609-623.

36. World Health Organization (2007) Reducing Salt Intake in Populations. WHO Document Production Services. Geneva: WHO.

37. Dötsch M, Busch J, Batenburg M, et al. (2009) Strategies to reduce sodium consumption: a food industry perspective. Crit Rev Food Sci Nutr 49, 841-851.

38. Lawrence G, Salles C, Septier C, et al. (2009) Odour-taste interactions: a way to enhance saltiness in low-salt content solutions. Food Qual Pref 20, 241-248.

39. Drewnowski A \& Schwartz M (1990) Invisible fats: sensory assessment of sugar/fat mixtures. Appetite 14, 203-217.

40. Drewnowski A, Shrager EE, Lipsky C, et al. (1989) Sugar and fat: sensory and hedonic evaluation of liquid and solid foods. Physiol Behav 45, 177-183.
41. Abdallah L, Chabert M, Le Roux B, et al. (1998) Is pleasantness of biscuits and cakes related to their actual or to their perceived sugar and fat contents? Appetite 30, 309-324.

42. Ricketts CD (1997) Fat preferences, dietary fat intake and body composition in children. Eur J Clin Nutr 51, 778-781.

43. Stewart JE, Feinle-Bisset C, Golding M, et al. (2010) Oral sensitivity to fatty acids, food consumption and BMI in human subjects. Br J Nutr 104, 145-152.

44. Gibson EL \& Wardle J (2001) Effect of contingent hunger state on development of appetite for a novel fruit snack. Appetite 37, 91-101.

45. Nicklaus S, Boggio V, Chabanet C, et al. (2004) A prospective study of food preferences in childhood. Food Qual Pref 15, 805-818.

46. Drewnowski A \& Gomez-Carneros C (2000) Bitter taste, phytonutrients, and the consumer: a review. Am J Clin Nutr $\mathbf{7 2}$, $1424-1435$.

47. World Health Organisation (2004) Fruit and Vegetables for Health. Kobe, Japan: WHO.

48. Havermans RC, Ronald Ross W \& Victor RP (2010) Increasing children's liking and intake of vegetables through experiential learning. In Bioactive Foods in Promoting Health, 1st ed., pp. 273-283 [RR Watson and VR Preedy, editors]. Oxford: Academic Press.

49. Zeinstra GG, Koelen MA, Kok FJ, et al. (2010) The influence of preparation method on children's liking for vegetables. Food Qual Pref (Epublication ahead of print version 4 January 2010).

50. Issanchou S \& Nicklaus S (2006) Measuring consumers perception of sweet taste. In Optimising Sweet Taste in Foods, 1st ed., pp. 97-131 [WJ Spillane, editor]. Cambridge: Woodhead Publishing Limited.

51. Pepino MY \& Mennella JA (2006) Children's liking of sweet tastes and its biological basis. In Optimising Sweet Taste in Foods, 1st ed., pp. 54-65 [WJ Spillane, editor]. Cambridge: Woodhead Publishing Limited.

52. James J, Thomas P, Cavan D, et al. (2004) Preventing childhood obesity by reducing consumption by carbonated drinks: cluster randomised controlled trial. BrMed J328, 1237.

53. Rolls BJ, Engell D \& Birch LL (2000) Serving portion size influences 5-year-old but not 3-year-old children's food intakes. J Am Diet Assoc 100, 232-234.$$
\text { foods. Physiol Behaw 45. 177-183. }
$$ 